Research Article

\title{
Dynamic Performance Evaluation of Concrete Building Using Low-Yield Point Steel Shear Panels
}

\author{
Nima Marzban (iD ${ }^{1}$ and Parisa Esmaeiltabar Nesheli ${ }^{2}$ \\ ${ }^{1}$ Department of Civil Engineering, Tabari Non-Profit Higher Education Institute, Babol, Iran \\ ${ }^{2}$ Department of Civil Engineering, Babol University of Technology, Babol, Iran \\ Correspondence should be addressed to Nima Marzban; nima.marzban@tabari.ac.ir
}

Received 8 May 2021; Revised 25 May 2021; Accepted 5 June 2021; Published 14 July 2021

Academic Editor: S. Mahdi S. Kolbadi

Copyright (c) 2021 Nima Marzban and Parisa Esmaeiltabar Nesheli. This is an open access article distributed under the Creative Commons Attribution License, which permits unrestricted use, distribution, and reproduction in any medium, provided the original work is properly cited.

\begin{abstract}
Steel shear walls are a novel component in the field of construction. It has been of special interest to structural engineers for the reinforcement of steel buildings for the recent decades. Its unique features have attracted more attention, and its features are economical, easy to implement, light weight compared to similar systems, high ductility, fast installation, high energy absorption, and a significant reduction in residual stress in the structure. All the reasons made researchers think about studying its use in the repair of concrete buildings. Because this system has a low weight, it does not add extra load to the structure, and even with its connections, it strengthens the beams and columns around it. The design of this system in concrete buildings does not seem to be economical except in the case of restoration. In this paper, preliminary explanations of the steel shear wall are presented for more familiarity, and in the following sections, the study of reinforcement and repair of concrete structures will be studied and its difference with the low-yield point will be considered. Finally, the test results will be reviewed. The results of this study show that LYP steel shear panels cause a lot of energy loss and absorption, which is very useful in the safety of buildings exposed to severe earthquakes.
\end{abstract}

\section{Introduction}

In recent years, steel shear wall (SSW) has attracted a considerable attention mainly because of its ability to harness lateral loads arising from earthquake. The new phenomenon has been utilized in construction of new buildings, as well as reinforcement of existing ones, especially in earthquake-prone areas such as the US and Japan. A 50\% reduction in the amount of steel has been reported when it comes to using moment steel frames. One of the many advantages of SSWs is its simple system [1]. Therefore, all engineers, technicians, and technical workers could run it only by relying on their skills. The SSW system is as precise as other steel constructions, and it is highly likely that its reliability would increase in the light of preserving standards. As its parts are constructed in the factory and then put together in the construction site, so it is viewed as a cheap, time-saving system [2]. The SSW is thought of as the stiffest bracing X-shaped system. Moreover, as it is easy to disassemble, SSW possesses all good points of other bracing systems [3].

Furthermore, it has suggested good efficiency compared to other bracing systems because of its behavior in the plastic environment, as well as energy absorption. Regarding diversity in materials and junctions, pressures are better balanced against lateral loads in SSWs compared to other resistant structures, such as frames and bracing systems, in which materials are gathered together and junctures are centralized [4]; moreover, SSWs suggest a better behavior in the plastic environment. Findings suggested a 25\% increase in capacity of SSWs to harness disasters such as earthquake, storm, and explosion, compared to other systems such as moment shear frames (Figure 1). The SSW system had been used in research laboratories with a capacity of $6670 \mathrm{kN}$ [6]. Reports supported the preliminary findings that the SSW system has high flexibility. Regarding the importance of the 


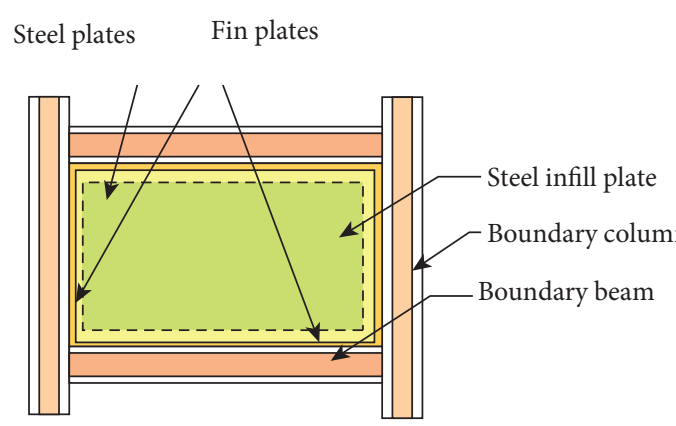

(a)

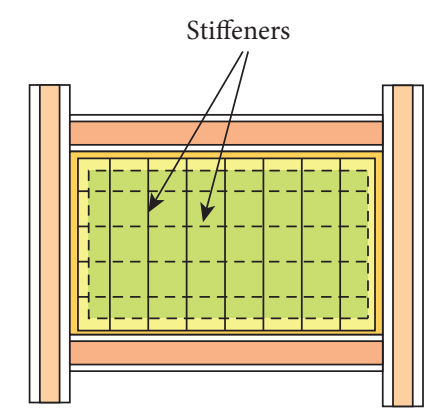

(b)

FIGURE 1: A scheme of a steel shear wall (SSW) in steel structures in the presence and absence of a stiffener [5]. (a) Unstiffened steel shear wall. (b) Stiffened steel shear wall.

research plan in order to make the US federal buildings resistant against earthquake, storm, and explosion, the National Foundation for the US Science, as well as the US Public Services, budgeted it [7].

\section{Material and Methods}

2.1. Buildings with SSWs. The system was first used in the Sylmar hospital in Los Angles, California. Shijo Konomora 3 is one of the many high-rise buildings constructed by the SSW system in Japan. The 51-story building is 211 meters in height. Five stories, namely, 27 meters, of the building is located beneath the ground. A SSW system has been utilized in central kernels of the building around elevators and staircases, as well as facility raisers. By the same token, for the purpose of reinforcing the structure, the mentioned panel has been also used in a medical center in Charlestoon. The building has been destroyed in an earthquake in 1963. It has been constructed on an area of 32,500 square meters that is made up of multiple 1-5 story buildings. In 1995, a massive earthquake hit Hyogoken-Nanbu and lots of people were killed [8]. Buildings which have been built before 1981 and especially before 1971 went through severe damages to such an extent that some of them collapsed. It suggests that old provisions concerning designing of buildings have not properly considered seismic loads, as well as structural flexibility [9].

In 1999, a big earthquake hit Chi-Chi, Taiwan, which led to great damages to the city and buildings [10]. Again, those buildings which have been designed and built before 1983 were destroyed [11]. As a result, all provisions when it came to earthquake were nullified and revised right after the earthquake. Seismic regional coefficients were developed for different parts of Taiwan. For example, acceleration of earthquake in Taichung was decreased from 23.0 to 33.0. As a result, almost all buildings in that region were reinforced according to newly made designing provisions. The project aimed to increase and improve seismic stability of buildings in which reinforced concrete has been used. The project made up of three objectives [12]. Finding out how much seismic stability is needed for buildings built with reinforced concrete according to the new provision, the problem of forces leads to the adjacent buildings due to over- displacement, and studying about two methods when it came to capability of steel shear panels, as well as steel braces' absorbing energy in order to improve seismic resistance of existent buildings [13].

2.2. Seismic Characteristics of LYP SSWs. SSWs improve seismic resistance of buildings. As thin steel plates are flexible, it absorbs limited energy [14]. Recently, thanks to newly founded methods and technologies in the field of steel, we have access to new steel plates. Lower yield point and more increase in height are defining characteristics of steel plates of this type which lead to an increase in flexibility and energy absorption before bursting [15]. Having lower yield point is another defining characteristic of SSWs which increases both plastic area and energy absorption. Absorbing much more energy characterizes SSWs built with LYP. Such panels, just like SSWs, are built by taking seismic loads into account. Thanks to the features, the SSW system is used as a friction damper to mitigate seismic energy [16]. These steel dampers have greater stability to absorb energy; moreover, in no way do they need maintenance than other dampers. It is important to note, however, that yield point and end point of LYP plates will be affected by shear strain forces [17]. The present research aimed to study how strain and loading manner would affect characteristics related seismic resistance of the under study plate panel. Experiments suggest how behavior of shear panels built with LYP steel changes under different loading speeds and incremental displacements [18].

2.3. Experiments on SSWs Built with LYP. Steel shear panels built with low-yield point steel is considered as a leading factor to absorb energy. Designing and developing such panels help to either absorb or waste much seismic energy. However, structural behavior of such panels is affected by the amount of strain. Nine samples were utilized to estimate behavior of these panels through various loadings [19]. Figure 2 illustrates how samples have been developed. The proportion of width to diameter of the panel has been assumed 50. External edges have been trimmed in order to prevent from fraction of joints among edges, panels, and the plate beneath the column. This would prevent from 


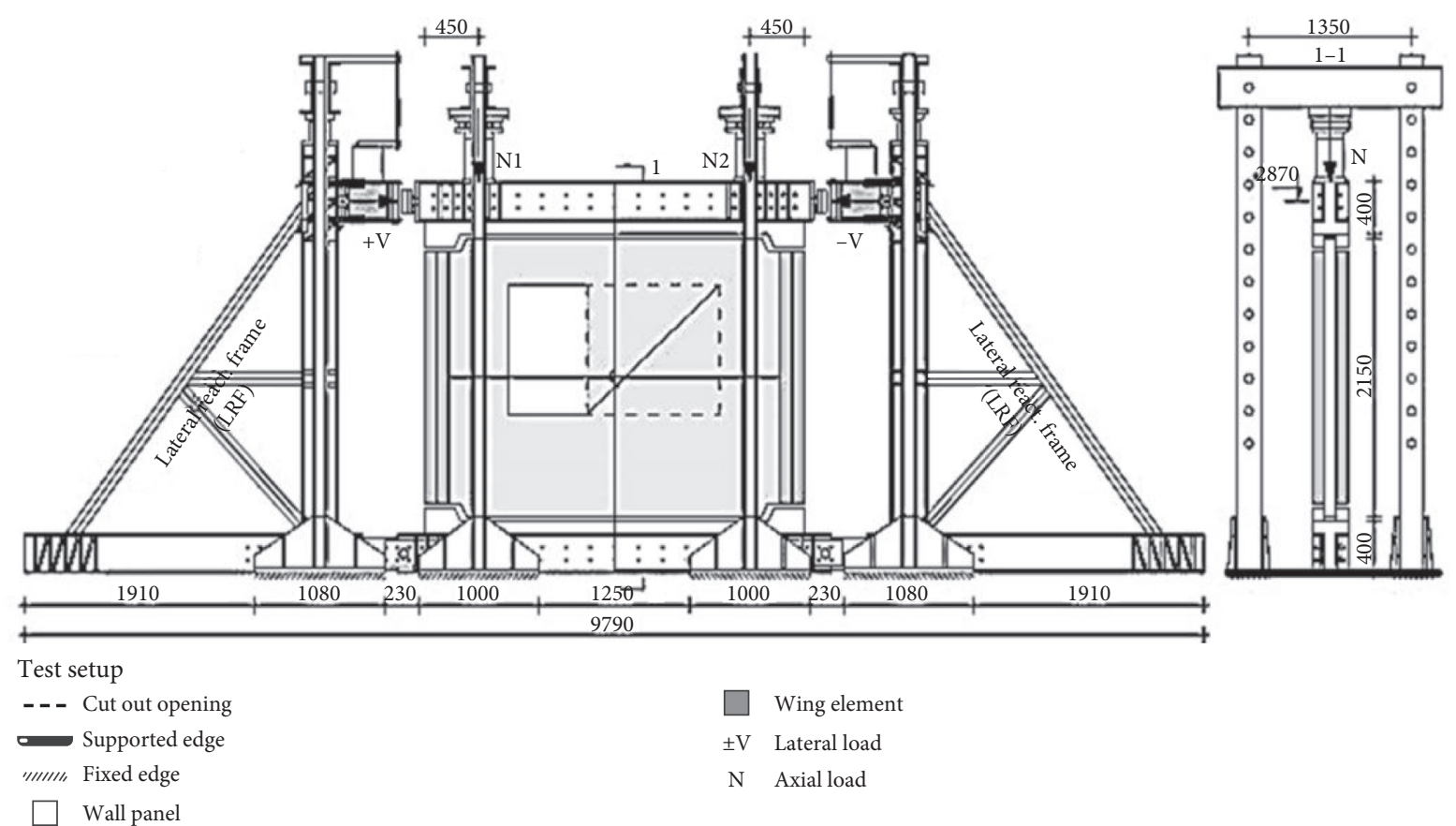

FIGURE 2: Experiment setup [20].

concentration of pressure and diversion of the plate into the aforementioned plastic area [21]. The history of loading the steel shear panel has been experimented in the current research. Moreover, three different loading speeds, namely 2, 5 , and $100 \mathrm{~mm} / \mathrm{sec}$, have been selected.

Gradual loading has been exercised instead of seismic loading in order to achieve strain speed for the samples. Furthermore, three different displacements have been used in each experimental loading. The experiment was stopped as soon as resistance of the structure became less than $80 \%$ of the end resistance. Table 1 shows results of the experiment.

\section{Results and Discussion}

3.1. Test Method. The concrete panel has been developed on a scale of 8.0. Figure 3 illustrates details of the concrete panel. The first panel designed according to MRF has been tested in the absence of reinforcement. The second one was a bracing built by LYP100 steel according to BIB-LYP. The third bracing has been developed by A36 steel according to BIBA36. The forth sample has also been developed by a steel shear wall built by LYP100 steel.

As can be seen from Figure 3, A36 steel possesses a yield point as much as the bracing built by LYP. Moreover, as can be seen from Figure 3, A36 SSW possesses a yield point as much as the bracing built by LYP. The reinforcing parts, such as the bracing and SSWs, are connected to a steel panel which has been made up of four $\mathrm{H}$-shaped panels with the dimensions $200 * 200 * 8 * 12$. The shorter axis of $\mathrm{H}$ was plunged off by the concrete panel [23]. Shear hobnails had been welded to $\mathrm{H}$-shaped plates. In the same token, both bracings and SSWs have been connected to the concrete panel along the steel one. Table 2 gives information about mechanical characteristics of steel [24]. As can be seen from data, compressive resistance of tested concrete for MRF, BIB-LYP, BIB-A36, and SSW-LYP were 21.8, 20.7, 25, and 23.7 MPa, respectively. From Figure 3, it can be seen that cyclic loading was done through reciprocal movement of a jack firmly fastened to a stable column.

Figure 4 gives information about hysteresis behavior when it comes to shear panels. Studies show that their relative rotation is over $5 \%$, that is to say, it is more than expected lateral displacement of the structure. As a result, buildings are likely to destroy when their relative rotation is over $2.5 \%$. Changes in transformation around the element and expected transformation, as well as lateral transformation angle by $5 \%$, seem to be sufficient for shear panels. As can be seen from Table 2, the angle of later transformation in all samples tested was over $5 \%$. According to data, there is $16 \%$ difference between slow and fast loadings.

By increasing steady loading and considering the effect of loading ratio on the total amount of energy dissipation, differences in the final resistance of a LYP steel shear panel is disregarded [25]. Figure 4 shows that the steel panel which has been tested possesses considerable resistance and energy absorption, and it is indifferentiable to displacement during loading or movement. Amount of energy wasted during each seismic loading remains constant. The characteristics of the load-displacement graph is severely affected by shear strain of thin steel plates [26].

Final resistance is gradually decreased when a shear strain occurs. Amount of final transformation of the shear panel is affected by the ratio of width to diameter. In the present research, the ratio of width to diameter is assumed 50 , and as soon as the lateral transformation angle is adjusted to $4 \%$, shear strain is started. Delay in shear strain has 
TABLE 1: Characteristics of steel.

\begin{tabular}{lccc}
\hline Percentage of increased length & Strain resistance $(\mathrm{MPa})$ & Final resistance $(\mathrm{MPa})$ & Type of steel \\
\hline 50 & 250 & 100 & LYP 16 mm \\
45 & 275 & 95 & LYP 5 mm \\
30 & 460 & 320 & A36 16 mm \\
20 & 665 & 430 & Rebar no. 6 \\
20 & 600 & 420 & Rebar no. 3 \\
30 & 360 & 260 & Rebar no. 4 \\
\hline
\end{tabular}

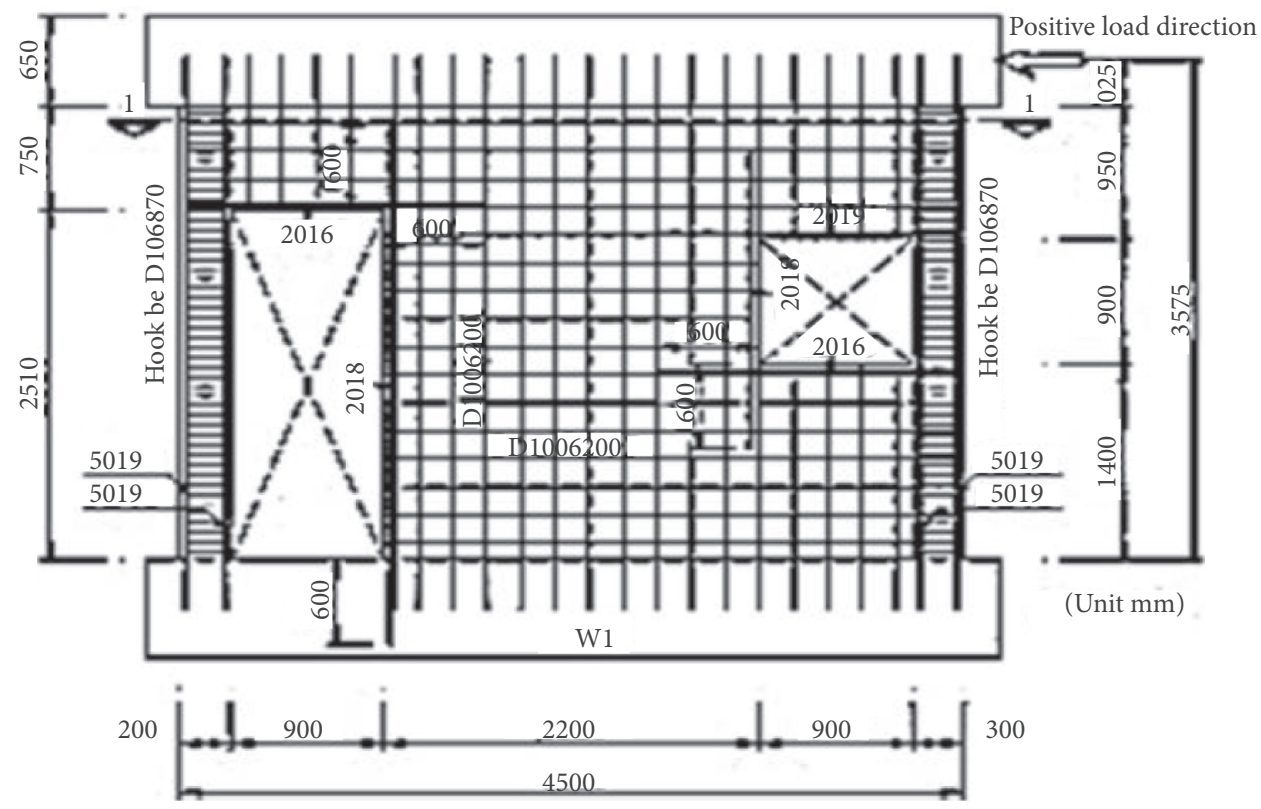

FIGURE 3: Scheme of a reinforced concrete panel [22].

TABLE 2: Results obtained from a steel shear wall built with LYP.

\begin{tabular}{lccc}
\hline Sample & Ultimate strength & $v$ & Rad/sec \\
\hline No. 1 & 205 & 2.5 & 0.01 \\
No. 2 & 230 & 50 & 0.2 \\
No. 3 & 220 & 60 & 0.3 \\
No. 4 & 210 & 100 & 0.4 \\
\hline
\end{tabular}

nothing to do with increased flexibility in the shear panel; however, decreased damages to nonstructural parts are relevant to the shear panel. Figure 5 gives information about total amount of save energy in all tested panels.

As can be seen from Figure 6, total amount of wasted energy has nothing to do with loading and increased displacement. As the seismic period has a random nature, studies show that energy is totally irrelevant to the history of loading that is considered as one of the many advantages of shear panels over seismic dampers. In shear panels, energy dissipation remains constant under a random loading cycle. As a result, steel panels prove to be effective to enforce buildings. The next section deals with experimental studies concerning reinforcement of concrete panels by virtue of steel Shear dampers (Figure 7). The results illustrate that buildings which have not been constructed according to recent designing standards are not very good at dealing with seismic loads and would go through severe damages. For example, such buildings in Taiwan are typically made up of reinforced concrete and are needed to be reinforced against seismic loads (Figure 8). Tests have proved that moment as well as steel shear panels possess high resistance and flexibility and stable hysteresis rings. Braced panels with bracing consisted of porter as well as bracing parts for carrying lateral loads (Figure 9). 


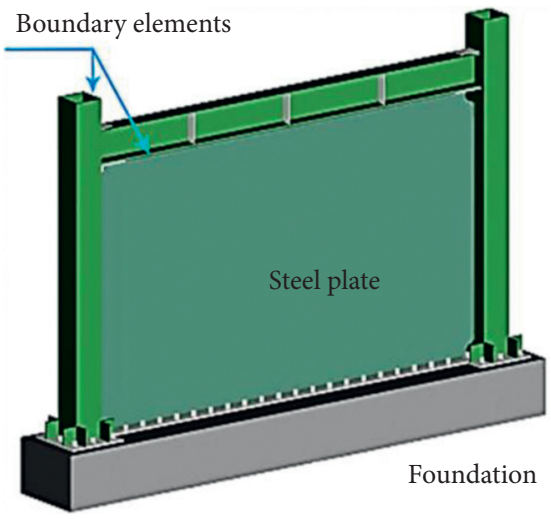

(a)

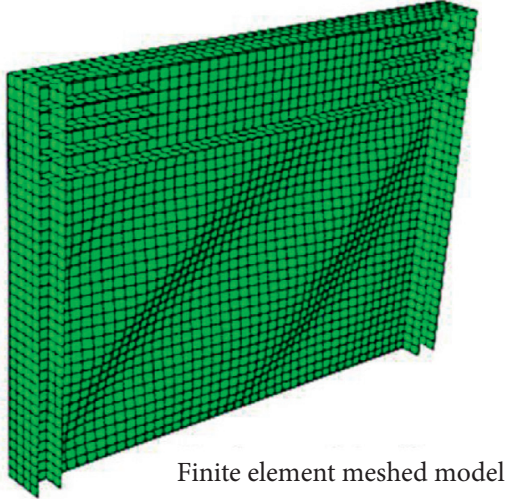

(b)

FIgURE 4: Longitudinal and cross section of the sample.

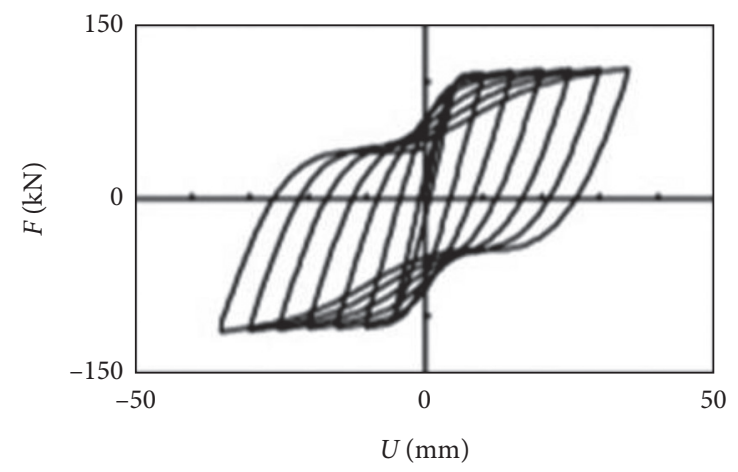

(a)

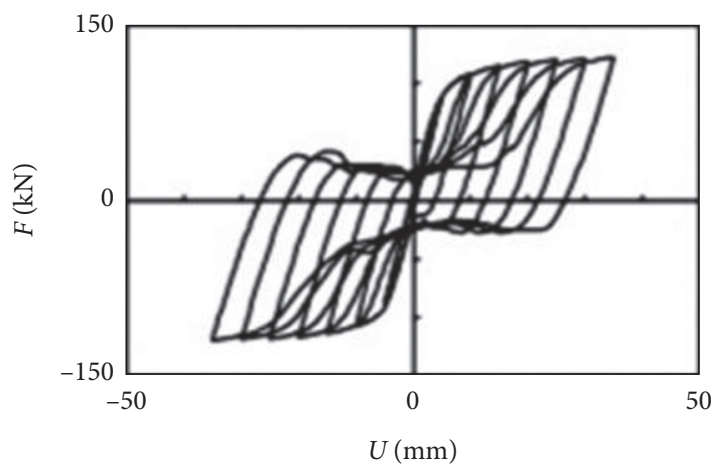

(c)

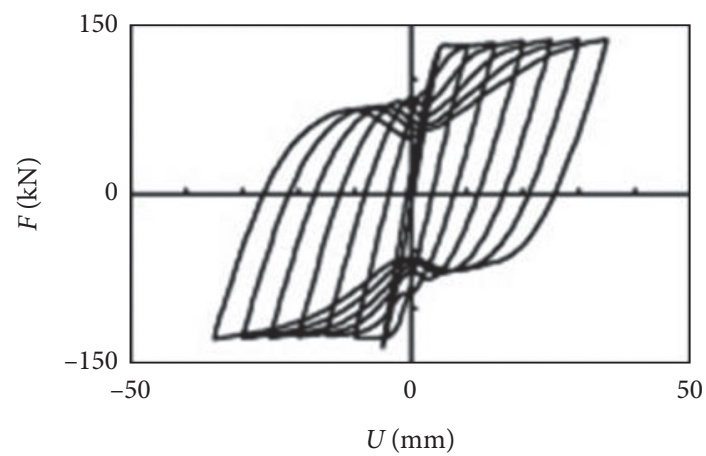

(b)

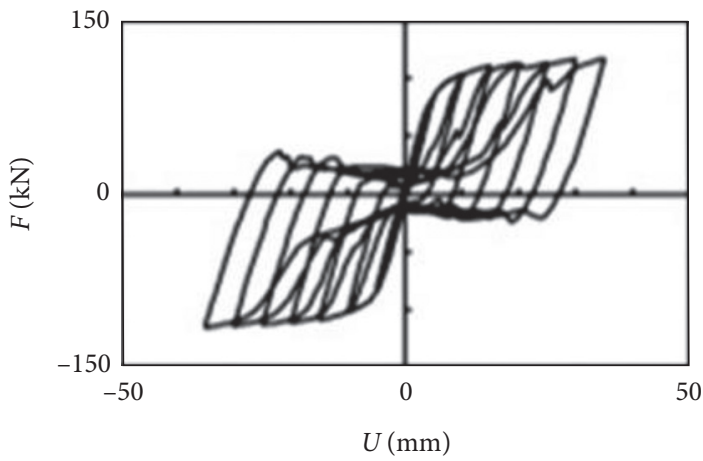

(d)

FiguRE 5: Hysteresis behavior of steel shear panels.

Figure 10 represents a ring-shaped hysteresis load-displacement for the given panel. Comparing the panel in the absence of bracing and stiffener, as well as considering resistance of all panel reinforcements, we achieved good results. Consider Figure 11 which plots axial load against transformation in the form of hysteresis rings for the bracing built with LYP steel. Moreover, Figure 11 represents hysteresis rings when it comes to shear load versus horizontal displacement. Experiments on SSWs provided asymmetric results, and data obtained from the tests are available in Table 3. Results prove preventing from strain in bracing as well as the SSW system has a big effect on reinforcement of panels. Stiffness, resistance, and flexibility of panels after reinforcement function as a leading factor concerning connection between both concrete and steel frames. Bracings improve resistance and flexibility. However, there is room for study about details when it comes to reinforcement of panels used in SSWs. 


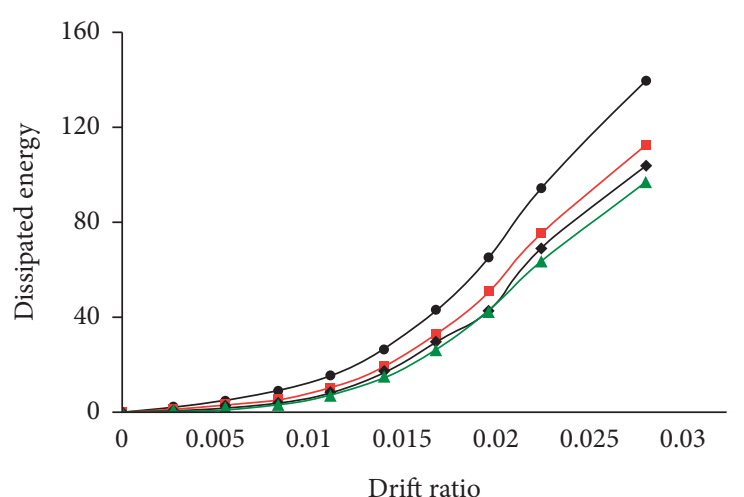

(a)

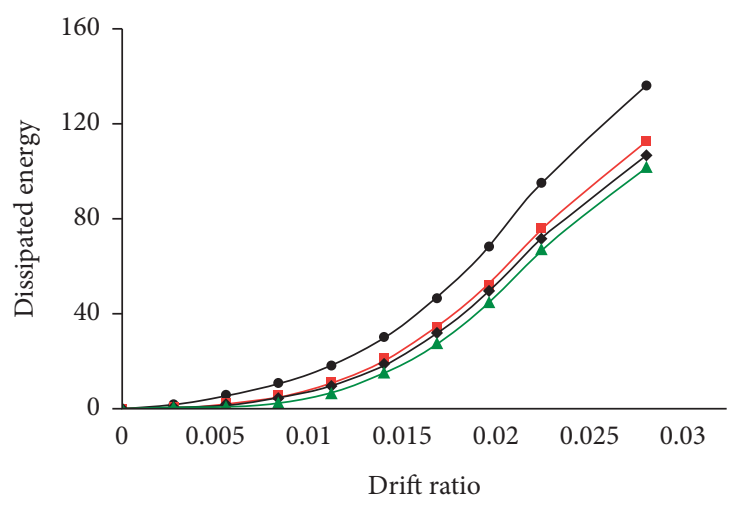

(c)

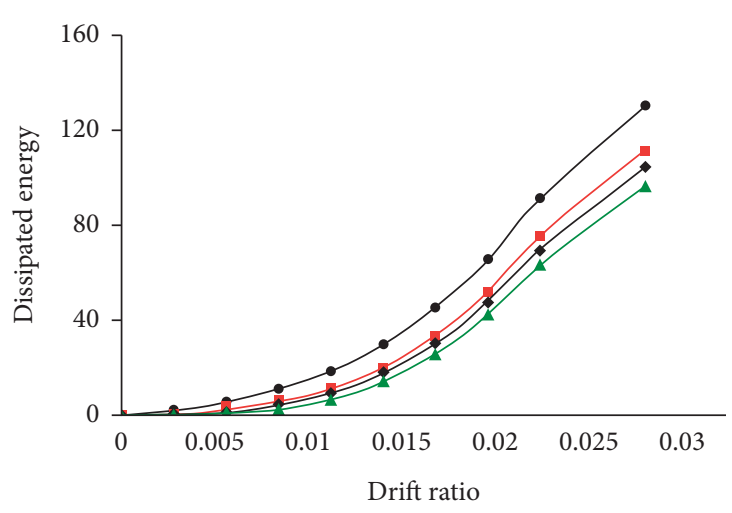

(b)

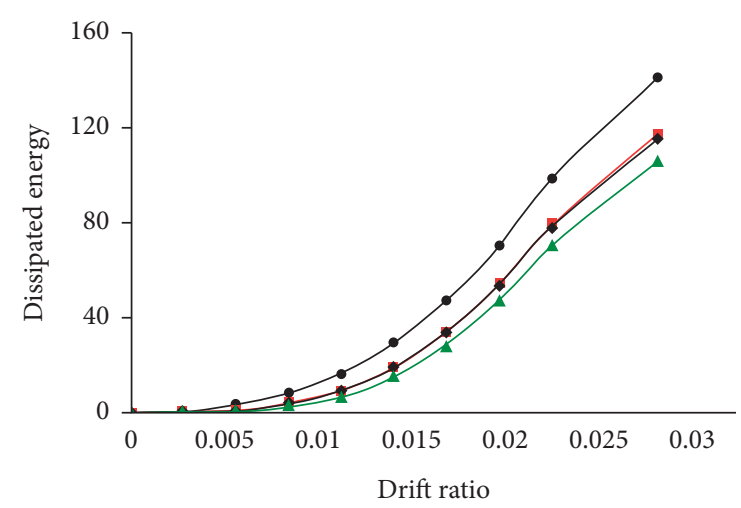

(d)

FIGURE 6: Dissipated energy in samples.

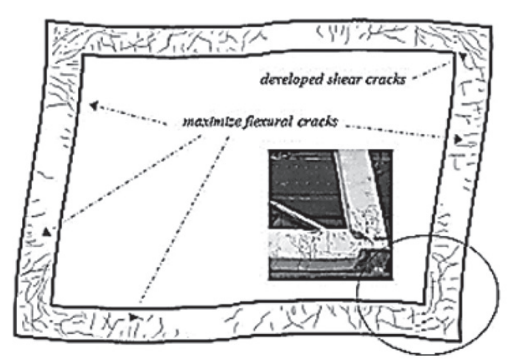

(a)

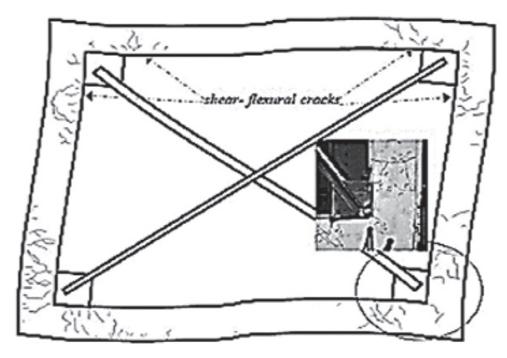

(b)

FIgURE 7: Cracks developed in a reinforced concrete panel with a bracing [27].

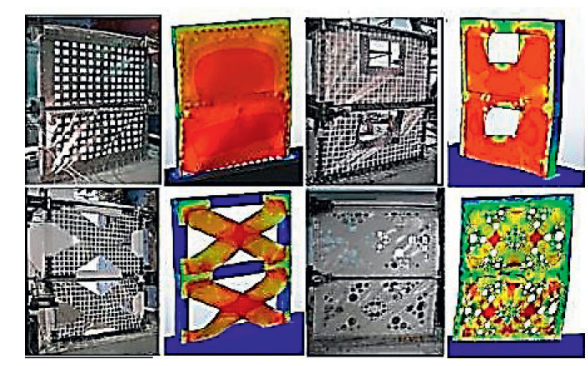

FIGURE 8: Cracks developed in a reinforced concrete panel with a SSW [28]. 


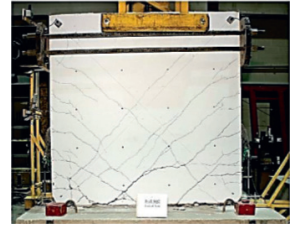

(a)

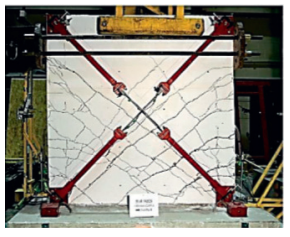

(b)

FIgURE 9: Cracks developed in a reinforced concrete panel with an A36 bracing [29].

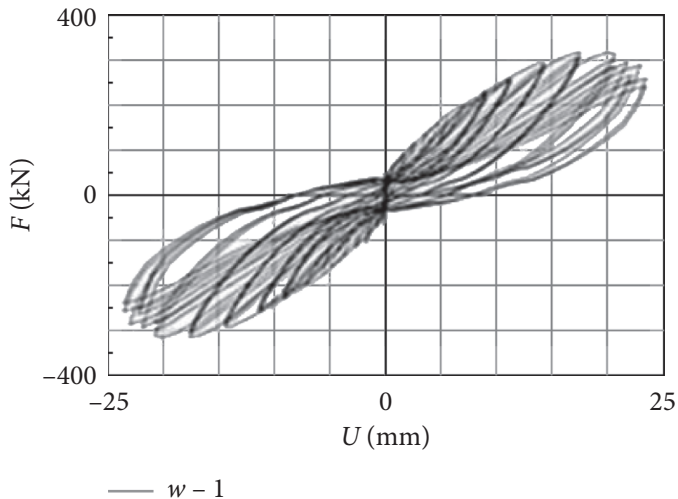

(a)

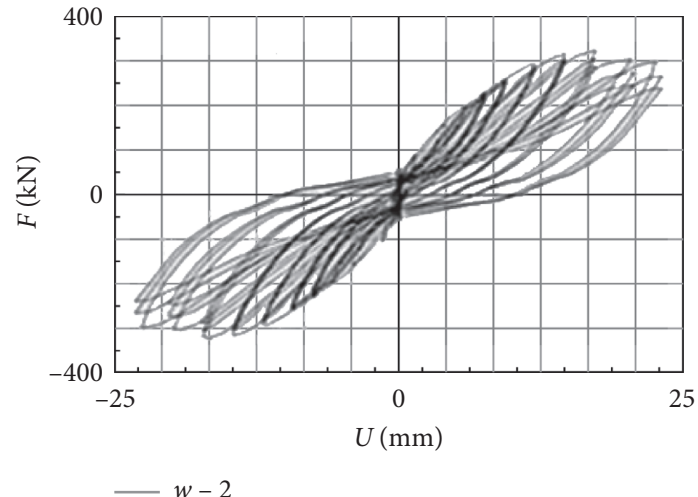

(b)

FIgURE 10: Hysteresis diagram of the reinforced concrete panel with a bracing.

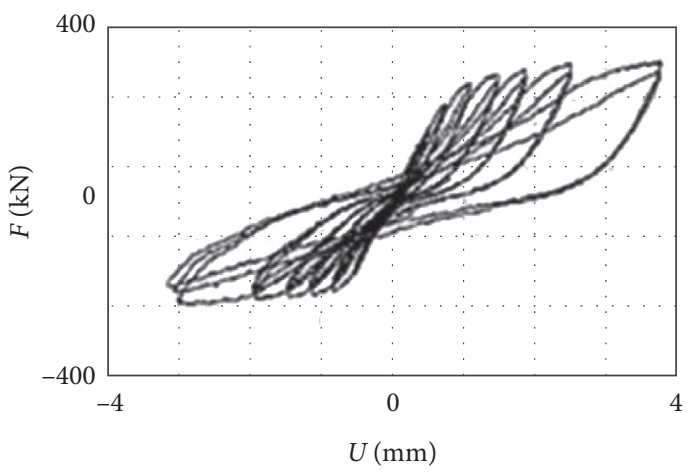

(a)

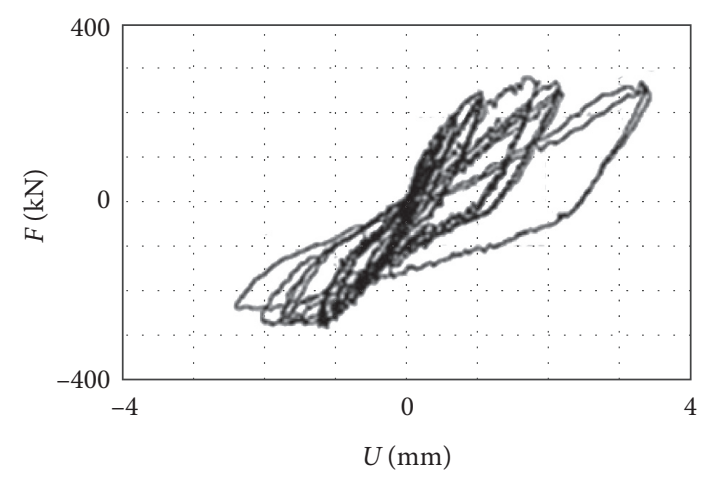

(b)

FIGURE 11: Hysteresis diagram of the reinforced concrete panel with a SSW.

TABLe 3: Test results.

\begin{tabular}{lccc}
\hline Sample & Py & DispMAX & Peak \\
\hline Reinforced concrete panel with a bracing & 115 & 20 & 160 \\
Reinforced concrete panel with a SSW & 325 & 4 & 800 \\
$\begin{array}{l}\text { A reinforced concrete panel with a A36 } \\
\text { bracing }\end{array}$ & 330 & 6 & 795 \\
\hline
\end{tabular}

\section{Conclusion}

Both yield point and final resistance of steel are affected by the strain ratio. Moreover, final resistance of shear panels built with LYP steel has much to do with loading speed. To put it simply, when loading was fast, final resistance increased by $16 \%$ than when it was slow. Developing and constructing LYP shear panels require a $5 \%$ relative rotation which causes higher energy dissipation. When the shear panel is loaded, local bending occurred. So, strain occurred when loading increased. As a result, the panel goes through an external arch which would result in strain in the cross section. When the panel is bended, external bonds absorb energy. In other words, first, middle of the plate absorbs energy and it gradually reaches the yield point. Then, energy absorption is transferred to the panel and finally the whole plate reaches the yield point which leads to energy absorption and dissipation. 


\section{Data Availability}

Requests for access to these data should be made to the corresponding author email address: nima.marzban@ tabari.ac.ir.

\section{Conflicts of Interest}

The authors declare that there are no conflicts of interest regarding the publication of this paper.

\section{References}

[1] Y. Zhang and X. Zhan, "Study on seismic behavior of steel frame-steel shear wall with assembled two-side connections," Mathematical Problems in Engineering, vol. 2019, Article ID 3024912, 15 pages, 2019.

[2] S. M. R. Mortazavi, M. Ghassemieh, and M. S. Ghobadi, "Research on the behavior of the steel plated shear wall by finite element method," Journal of Structures, vol. 9, no. 1, pp. 1-20, 2013.

[3] A. Gul, S. Khan, B. Alam et al., "Experimental study on the structural behavior of cast in-situ hollow core concrete slabs," Civil Engineering Journal, vol. 12, no. 3, pp. 100-124, 2020.

[4] M. J. Afshari, A. Asghari, and M. Gholhaki, "Shear strength and stiffness enhancement of cross-stiffened steel plate shear walls," International Journal of Advanced Structural Engineering, vol. 11, no. 1, pp. 179-193, 2019.

[5] A. Astaneh-Asl, X. Qian, and Y. Shi, "Application of steel shear walls toward more resilient structures," Resilient Structures and Infrastructure, vol. 1, pp. 3-46, 2019.

[6] S. M. Seyed Kolbadi, H. Piri, A. Keyhani, S. M. Seyed-Kolbadi, and M. Mirtaheri, "Nonlinear seismic performance evaluation of flexural slotted connection using endurance time method," Shock and Vibration, vol. 2020, Article ID 8842230, 15 pages, 2020.

[7] T. M. Roberts, "Seismic resistance of steel plate shear walls," Engineering Structures, vol. 17, no. 5, pp. 344-351, 1995.

[8] NIST 901, The January 171995 Hyogoken-Nanbu (Kobe) Earthquake: Performance of Structure, Lifelines and Fire Protection Systems, U.S. Department of Commerce, Technology Administration, NIST, Gaithersburg, MD, USA, 1996.

[9] J. Wang and H. Zhao, "High performance damage-resistant seismic resistant structural systems for sustainable and resilient city: a review," Shock and Vibration, vol. 2018, Article ID 8703697, 32 pages, 2018.

[10] K.-F. Ma, C.-T. Lee, Y.-B. Tsai, T.-C. Shin, and J. Mori, "The Chi-Chi, Taiwan earthquake: large surface displacements on an inland thrust fault," EOS, Transactions American Geophysical Union, vol. 80, no. 50, pp. 605-620, 1999.

[11] F. Rahimi, R. Aghayari, and B. Samali, "Application of tuned mass dampers for structural vibration control: a state-of-theart review," Civil Engineering Journal, vol. 6, no. 8, pp. 1622-1651, 2020.

[12] M. A. E.-N. Kandil, A. H. Abdelraheem, M. Mahdy, and A. M. Tahwia, "Effect of changing properties of wythes in precast structural sandwich panels," Civil Engineering Journal, vol. 15, no. 1, pp. 128-135, 2020.

[13] D. Guangqian, Z. Meng, and W. Shijie, "Evaluation of seismic performance of reinforced concrete frame structures in the context of big data," Complexity, vol. 2019, Article ID 4126739, 14 pages, 2019.

[14] O. V. Mkrtycheva and M. S. Busalovab, "Calculation of reinforced concrete structures with a set seismic stability level on an earthquake," Procedia Engineering, vol. 153, no. 1, pp. $475-482,2016$.

[15] Z. Tadeh and J. Zhang, "Seismic design and behavior of low yield point steel plate shear walls," International Journal of Steel Structures, vol. 15, no. 1, pp. 135-151, 2015.

[16] S. M. Seyed Kolbadi, H. Davoodian, S. Mohamad, and S. Kolbadi, "Evaluation of nonlinear behavior of reinforced concrete frames by explosive dynamic loading using finite element method," Civil Engineering Journal, vol. 3, no. 12, pp. 1-15, 2017.

[17] R. Aghayari and S. Dardaei, "Evaluating the effect of the thickness and yield point of steel on the response modification factor of RC frames braced with steel plate," KSCE Journal of Civil Engineering, vol. 22, no. 1, pp. 1865-1871, 2018.

[18] A. Tiganescu, B. Grecu, and I. G. Craifaleanu, "Dynamic identification for representative building typologies: three case studies from Bucharest area," Civil Engineering Journal, vol. 6, no. 3, pp. 418-430, 2020.

[19] A. Ghamari and H. Haeri, "Improving the behavior of high performance steel plate shear walls using low yield point steel," Case Studies in Construction Materials, vol. 14, no. 1, pp. 1-15, 2021.

[20] C. Todut, D. Dan, and V. Stoian, "Theoretical and experimental study on precast reinforced concrete wall panels subjected to shear force," Engineering Structures, vol. 80, no. 1, pp. 323-338, 2014.

[21] Z. Tadeh, "Seismic performance and design of steel plate shear walls with low yield point steel infill plates," UCLA Electronic Theses and Dissertations, University of California, Los Angeles, CA, USA, 2013.

[22] Y.-C. Ouab, L. Hoang, and H. Roh, "Cyclic behavior of squat reinforced concrete walls with openings typical of exterior walls of row houses in Taiwan," Engineering Structures, vol. 195, no. 15, pp. 231-242, 2019.

[23] X. Wu, W. Guo, P. Hu, D. Bu, X. Xie, and Y. Hu, "Seismic performance evaluation of building-damper system under near-fault earthquake," Shock and Vibration, vol. 2020, Article ID 2763709, 21 pages, 2020.

[24] D. Kim, E. H. Sung, K.-S. Park, and J. Park, "Evaluation of seismic performance and effectiveness of multiple slim-type damper system for seismic response control of building structures," The Scientific World Journal, vol. 2014, Article ID 189106, 9 pages, 2014.

[25] A. Malhotra, T. Roy, and V. Matsagar, "Effectiveness of friction dampers in seismic and wind response control of connected adjacent steel buildings," Shock and Vibration, vol. 2020, Article ID 8304359, 21 pages, 2020.

[26] B. Wang, W. Yan, and H. He, "Mechanical performance and design method of improved lead shear damper with long stroke," Shock and Vibration, vol. 2018, Article ID 1623103, 18 pages, 2018.

[27] K. Ramin and M. Fereidoonfar, "Finite element modeling and nonlinear analysis for seismic assessment of off-diagonal steel braced RC frame," International Journal of Concrete Structures and Materials, vol. 9, no. 1, pp. 89-118, 2015.

[28] S. ZerrinKorrkmaz, "An analytical study about the use of steel plate shear walls to improve lateral rigidity of reinforced concrete framed structures," Latin American Journal of Solids and Structures, vol. 17, no. 7, pp. 1-20, 2020.

[29] W. Leonardo Cortés-Puentes and D. Palermo, "Seismic retrofit of concrete shear walls with SMA tension braces," Journal of Structural Engineering, vol. 144, no. 2, pp. 1-25, 2018. 